\title{
Precipitation Intensity Changes in the Tropics from Observations and Models
}

\author{
GUOJUn Gu AND ROBERT F. AdLER \\ Earth System Science Interdisciplinary Center, University of Maryland, College Park, College Park, Maryland
}

(Manuscript received 14 August 2017, in final form 16 March 2018)

\begin{abstract}
Tropical $\left(30^{\circ} \mathrm{N}-30^{\circ} \mathrm{S}\right)$ interdecadal precipitation changes and trends are explored for the satellite era using GPCP monthly analyses and CMIP5 outputs and focusing on precipitation intensity distributions represented by percentiles (Pct) and other parameters. Positive trends occur for the upper percentiles (Pct $\geq 70$ th), and become statistically significant for Pct $\geq 80$ th. Negative trends appear for the middle one-half percentiles ( $\sim 20$ th-65th) and are statistically significant for the 20th-40th percentiles. As part of these trends there is a decadal shift around 1998, indicating the presence of an interdecadal [Pacific decadal oscillation (PDO)] signal. For the lower percentiles (Pct $\leq 10$ th), positive trends occur, although weakly. The AMIP-type simulations generally show similar trend results for their respective time periods.

Precipitation intensity changes are further examined using four precipitation categories based on the climatological percentiles: Wet (Pct $\geq 70$ th), Intermediate (70th $>$ Pct $\geq 30$ th), Dry (30th $>$ Pct $\geq 5$ th), and No Rain (5th $>$ Pct $\geq 0$ th). Epoch differences of occurrence frequency between 1988-97 and 1998-2015 have spatial features generally reflecting the combined effect of the PDO and external forcings, specifically the anthropogenic greenhouse gas (GHG)-related warming based on comparisons with both AMIP and CMIP results. Furthermore, precipitation intensity over Wet zones shows much stronger changes than mean precipitation including a more prominent change around 1998 associated with the PDO phase shift. Trends also appear in the sizes of Intermediate and Dry zones, especially over ocean. However, changes in the sizes of Wet and No Rain zones are generally weak. AMIP simulations reproduce these changes relatively well. Comparisons with the CMIP5 historical experiments further confirm that the observed changes and trends are a combination of the effect of the PDO phase shift and the impact of anthropogenic GHG-related warming.
\end{abstract}

\section{Introduction}

There have been consistent research efforts to assess and understand global precipitation variation/change during the past three-plus decades (1979-present) in which satellite-based precipitation measurements with global coverage are available (e.g., Gu et al. 2007; Adler et al. 2008; John et al. 2009; Allan et al. 2010, 2014; Gu and Adler 2013; Gu et al. 2016; Adler et al. 2017), both for scientific significance and societal implications. Global mean precipitation derived from satellite- and gaugebased analyses such as the monthly product from the Global Precipitation Climatology Project (GPCP) (arguably the best at present) shows a very weak long-term trend during the post-1979 period (e.g., John et al. 2009; Gu and Adler 2013; Gu et al. 2016), even though significant warming exists in surface temperature. However, precipitation increase has been found in the deep tropics specifically over tropical oceans (e.g., Gu et al. 2007; John

\footnotetext{
Corresponding author: Guojun Gu,ggu@umd.edu
}

et al. 2009; Gu and Adler 2013). Evident regional precipitation changes have also been discovered across the globe (e.g., Gu and Adler 2013; Gu et al. 2016), although detailed physical mechanisms behind these changes still warrant further exploration in that various decadal/ multidecadal internal variabilities might have played a role, in addition to external (natural and anthropogenic) forcings (e.g., Seager and Naik 2012; Gu et al. 2016). It has been argued that a large portion of precipitation changes on the regional scale during this period, specifically regarding their spatial structures, might be dominated by dynamic factors including both anthropogenic [especially greenhouse gas (GHG)-related] circulation changes and decadal/multidecadal-scale internal variability such as the Pacific decadal oscillation (PDO) (e.g., Lu et al. 2007; Garfinkel et al. 2015; Seager and Naik 2012; Gu et al. 2016).

The enhancement of existent precipitation minus evaporation patterns under global warming $(\mathrm{GW})$ has been shown and extensively discussed in previous studies based on both model simulations and observations 
(e.g., Held and Soden 2006; Seager et al. 2010; Seager and Naik 2012; Liu and Allan 2013), which tend to confirm the concept of "wet-gets-wetter, dry-gets-drier" at least in the zonal-mean context. In general, there is a tendency of drying the (climatologically dry) subtropics and wetting the (moist) deep tropics especially along the intertropical convergence zone (ITCZ) and the middle to higher latitudes following global surface temperature increase, further confirming the importance of regional precipitation changes, and precipitation variations/ changes over various climatologically distinct zones. However, focusing only on mean precipitation amount at global grid cells or precipitation amount averaged over large domains, including tropical and global means, may result in losing detailed information on precipitation (intensity) distributions, which include likely precipitation intensity change over regions with distinct climatological characteristics (e.g., tropical wet and dry zones) and also possible location shifts and size changes of these regions. Different responses to surface temperature among precipitation intensity distributions (derived from daily and monthly precipitation products) have been described in past studies (e.g., Allan and Soden 2008; Liu et al. 2012; Lau and Wu 2007). Therefore, it is interesting to further examine decadal-scale variability/change in precipitation intensity distributions and variations in a variety of monthly precipitation percentiles (Pct) (and other parameters) for the tropical domain $\left(30^{\circ} \mathrm{N}-30^{\circ} \mathrm{S}\right)$.

Several studies have investigated precipitation changes in tropical wet and dry regions using both observations and model outputs (e.g., Liu and Allan 2013; Polson et al. 2013; Polson and Hegerl 2016), generally confirming intensified contrast between wet and dry regions under surface warming. The upper 30th and the lower 70th or 30th precipitation percentiles have been applied to define wet and dry regions, respectively, in these studies (e.g., Liu and Allan 2013; Polson et al. 2013). Here, a further step is made by defining three other zones based on long-term monthly precipitation percentiles, including Intermediate (30th-70th), Dry (5th-30th), and No-Rain (0-5th), in addition to the Wet region defined by the upper 30 percentiles as in Liu and Allan (2013) and Polson et al. (2013). We intend to examine precipitation intensity changes over these climatologically distinct zones, specifically the tropical wet and intermediate zones, and then make comparisons with variations and changes in mean precipitation amounts in the tropics (land, ocean, and land + ocean). It is likely that precipitation intensity and mean precipitation may respond differently to surface temperature warming, similar to differing responses of (high temporal resolution) precipitation extremes and mean precipitation (e.g., Allen and Ingram 2002). Different sensitivities of these two types of precipitation variables may further help identify effective additional indicators that could be used for monitoring decadal/trend-timescale precipitation variations and changes.

Furthermore, past studies have generally been only focused on precipitation intensity changes over various distinct regions (e.g., Liu and Allan 2013; Polson et al. 2013; Polson and Hegerl 2016). Since monthly precipitation percentiles in the tropics for each month were generally used to define wet and dry regions in these studies (e.g., Liu and Allan 2013; Polson et al. 2013), the sizes of these regions are fixed, although their geographical locations can vary with time. However, exploring whether and how there are any significant location shifts and size changes of the climatologically distinct zones following surface temperature increase is relevant and interesting as well, since it could provide an alternate view of the responses of the hydrological cycle to various mechanisms. There is evidence that the sea surface temperature (SST) threshold for tropical convection closely follows the change of tropical mean SST, resulting in roughly constant total fraction area of tropical deep convection and rainfall (Johnson and Xie 2010). This is also consistent with the result that the area of positive atmospheric net heating remains approximately constant following global surface warming, even though there is an evident expansion of warm SST zones in the tropics (e.g., Hoyos and Webster 2012). Hence, it is of interest to quantify whether any significant change might have happened in the sizes and geographical locations of the four climatologically distinct zones over tropical land and ocean during the satellite period, which has not been explicitly explored in past studies. Significant changes in the sizes and geographical locations of various zones might also be used as effective climatic indicators.

Finally, comparisons with the outputs from the stateof-the-art CMIP5 models will be made including both AMIP and CMIP historical full radiative forcing simulations, which can result in an evaluation of these models' skill in reproducing observed precipitation variations and changes and simulating forced variations and changes, respectively, and could also improve our understanding of what physical mechanisms might have driven those observed variations/changes during the satellite period. For example, while the AMIP runs, driven by evolving observed SST patterns, should reflect large-scale interdecadal (e.g., PDO) and interannual (e.g., ENSO) impacts, the ensemble means of CMIP coupled runs should generally show only the effects of external (anthropogenic and natural) forcings, including anthropogenic GHG-related surface warming. It should 
be further noted that model-observation differences might also be due to both model errors and possible issues with current observational data including GPCP.

The paper is organized as follows: Section 2 provides an introduction of the datasets applied in this study. Results and discussions are presented in sections 3, 4, and 5. A summary and concluding remarks are given in section 6

\section{Datasets}

The monthly precipitation product from the Global Precipitation Climatology Project (version 2.3) is used here (Adler et al. 2003; Huffman et al. 2009). This is a community-based analysis of global precipitation under the auspices of the World Climate Research Program (WCRP). The product is produced by merging a variety of data sources: passive microwave-based precipitation retrievals from the Special Sensor Microwave Imager (SSM/I) and the Special Sensor Microwave Imager Sounder (SSMIS), infrared (IR) rainfall estimates from geostationary and polar-orbiting satellites, and surface rain gauge analysis from the Global Precipitation Climatology Centre (GPCC) of the Deutscher Wetterdienst (DWD) in Germany. Archived on a global $2.5^{\circ} \times 2.5^{\circ}$ grid, the monthly product covers the entire post-1979 period (more details on the current version 2.3 are provided at http://gpcp.umd.edu/). This study is only focused on the post-1988 period (January 1988-December 2015) in which the passive microwave-based precipitation estimates are available.

Monthly precipitation outputs from the atmosphereonly (AMIP) simulations and the historical full (HistFull) radiative forcings experiments from multiple CMIP5 models (Taylor et al. 2012) are applied as well for comparisons and physical understanding (Table 1). Multimodel ensemble means are computed to limit atmospheric and oceanic internal variations for Hist-Full and atmospheric internal oscillations for AMIP by choosing the first realization from each model. The AMIP-type simulations are forced by observed SST and sea ice extent, and also by a variety of natural and anthropogenic radiative forcings used in the CMIP5 historical full radiative forcings experiments. All model outputs have been regridded to match the GPCP's global $2.5^{\circ} \times$ $2.5^{\circ}$ grid cells. The time period for AMIP is from January 1979 to December 2008. Since most of the CMIP5 historical full radiative forcings experiments are only up to December 2005, the outputs from the representative concentration pathway (RCP) 4.5 experiments are used to extend their temporal coverage to December 2012.

The NOAA Extended Reconstructed Sea Surface Temperature (ERSST) (version 4) is applied (Xue et al.
TABLE 1. List of CMIP5 models whose monthly precipitation outputs from AMIP and historical full radiative forcings and RCP 4.5 experiments are used in this study. (Expansions of acronyms are available online at http://www.ametsoc.org/PubsAcronymList.)

\begin{tabular}{|c|c|c|}
\hline Model name & $\begin{array}{c}\text { AMIP } \\
(1979-2008)\end{array}$ & $\begin{array}{l}\text { Hist-Full + RCP } 4.5 \\
\quad(1979-2012)\end{array}$ \\
\hline ACCESS1.0 & $\sqrt{ }$ & $\sqrt{ }$ \\
\hline ACCESS1.3 & $\sqrt{ }$ & $\sqrt{ }$ \\
\hline BCC-CSM1.1 & $\sqrt{ }$ & $\sqrt{ }$ \\
\hline BNU-ESM & $\sqrt{ }$ & $\sqrt{ }$ \\
\hline CanAM4 & $\sqrt{ }$ & \\
\hline CMCC-CM & $\sqrt{ }$ & \\
\hline CNRM-CM5 & $\sqrt{ }$ & $\sqrt{ }$ \\
\hline CSIRO-Mk3.6.0 & $\sqrt{ }$ & $\sqrt{ }$ \\
\hline EC-EARTH & $\sqrt{ }$ & \\
\hline FGOALS-g2 & $\sqrt{ }$ & $\sqrt{ }$ \\
\hline GFDL-CM3 & $\sqrt{ }$ & \\
\hline GISS-E2-H & & $\sqrt{ }$ \\
\hline GISS-E2-R & $\sqrt{ }$ & $\sqrt{ }$ \\
\hline HadGEM2-A & $\sqrt{ }$ & \\
\hline HadGEM2-ES & & $\sqrt{ }$ \\
\hline INM-CM4 & $\sqrt{ }$ & $\sqrt{ }$ \\
\hline IPSL-CM5A-LR & $\sqrt{ }$ & $\sqrt{ }$ \\
\hline MIROC5 & $\sqrt{ }$ & $\sqrt{ }$ \\
\hline MIROC-ESM & & $\sqrt{ }$ \\
\hline MIROC-ESM-CHEM & & $\sqrt{ }$ \\
\hline MPI-ESM-LR & $\sqrt{ }$ & $\sqrt{ }$ \\
\hline MPI-ESM-MR & $\sqrt{ }$ & $\sqrt{ }$ \\
\hline MRI-CGCM3 & $\sqrt{ }$ & $\sqrt{ }$ \\
\hline NCAR CCSM4 & $\sqrt{ }$ & $\sqrt{ }$ \\
\hline NorESM1-M & $\sqrt{ }$ & $\sqrt{ }$ \\
\hline
\end{tabular}

2003; Smith et al. 2008) to compute tropical mean SST anomalies. The PDO index is used to represent (internal) decadal/interdecadal-scale variability in the Pacific basin (downloaded from http://jisao.washington. edu/pdo/PDO.latest). The PDO index is defined as the first leading principal component of monthly SST anomalies north of $20^{\circ} \mathrm{N}$ in the Pacific Ocean with the global mean SST anomalies removed (Zhang et al. 1997; Mantua and Hare 2002). It should be mentioned that the PDO may not be a single physical mode, but results from a combination of various physical processes operating on different time scales both locally and remotely, including ENSO-related variability in the tropics (e.g., Newman et al. 2016).

\section{Variabilities and changes in annual monthly precipitation percentiles}

A variety of precipitation percentiles for each year are determined first for the tropical domain $\left(30^{\circ} \mathrm{N}-30^{\circ} \mathrm{S}\right.$; land + ocean) using GPCP monthly precipitation. Their long-term averages are computed and summarized in Table 2 for two time periods: 1988-2015 and 1979-2015. Although the differences between these two periods are 
TABLE 2. Long-term averages of annual precipitation percentiles $\left(\mathrm{mm} \mathrm{day}^{-1}\right)$ in the tropics $\left(30^{\circ} \mathrm{N}-30^{\circ} \mathrm{S}\right.$; land + ocean) for GPCP (1988-2015, and 1979-2015 in parentheses), AMIP (1979-2008), and CMIP5 Hist-Full (1979-2012). Bold font indicates percentiles defining the four precipitation categories (see text).

\begin{tabular}{lccc}
\hline \hline Percentile & GPCP & AMIP & Hist-Full \\
\hline 95th & $10.47(10.37)$ & 10.14 & 9.70 \\
90th & $8.28(8.20)$ & 8.61 & 8.38 \\
80th & $5.68(5.63)$ & 6.55 & 6.36 \\
70th & $\mathbf{3 . 8 7}(\mathbf{3 . 8 5})$ & $\mathbf{4 . 9 1}$ & $\mathbf{4 . 6 5}$ \\
65th & $3.12(3.12)$ & 4.22 & 3.98 \\
60th & $2.49(2.51)$ & 3.59 & 3.43 \\
50th & $1.53(1.57)$ & 2.54 & 2.54 \\
40th & $0.86(0.91)$ & 1.71 & 1.82 \\
30th & $\mathbf{0 . 4 4}(\mathbf{0 . 4 8})$ & $\mathbf{1 . 0 6}$ & $\mathbf{1 . 2 4}$ \\
20th & $0.20(0.22)$ & 0.58 & 0.74 \\
10th & $0.07(0.07)$ & 0.34 & 0.38 \\
5th & $\mathbf{0 . 0 2 6 ( 0 . 0 2 3 )}$ & $\mathbf{0 . 1 9}$ & $\mathbf{0 . 2 0}$ \\
\hline
\end{tabular}

relatively small, the focus of this study is on the period of 1988-2015 in which the microwave retrievals are available, as mentioned above (Adler et al. 2003; Huffman et al. 2009). Annual anomalies are then computed to explore their temporal variations and changes, specifically on interdecadal and trend time scales (Figs. 1a,b). For comparison, annual mean precipitation anomalies $\left(P_{\text {mean }}\right)$ are also depicted in Fig. 1d. Linear trends are estimated for these time series by means of linear regression, which are considered statistically significant if corresponding $p$ values are less than or equal to 0.05 . Significance tests are performed using the Student's $t$ test after taking into account the autocorrelation of time series, and the results are generally confirmed by the Mann-Kendall trend test. In general, there is an upward increase for the upper one-third of the GPCP percentiles (Pct $\geq 70 \mathrm{th}$ ), and the positive trends for the 80th, 90th, and 95 th percentiles are statistically significant. Tropical mean precipitation also has a significant positive trend during the period (Fig. 1d), likely resulting from mean SST increase (Fig. 2a); however, its magnitude for the mean value is much smaller than the trends for Pct $\geq$ 80th. A downward trend appears roughly for the middle one-half percentiles (approximately 20th-65th), with significant negative trends being seen for the 30th and 40th percentiles and relatively weak trends for the 20th and 50th percentiles. It is also noted that a decadal-scale shift appears around 1998 in the percentiles with opposite signs of change between these two groups, likely suggesting the impact of the PDO-related phase shift (Figs. 2b,c; e.g., Gu et al. 2016). For the lowest percentiles there is generally a weak and statistically insignificant positive trend. These results are generally in agreement with past studies (e.g., Liu and Allan 2013; Polson et al. 2013). Interannual variability is also evident in these time series. In particular, the ENSO effect can be readily seen for those high percentiles (i.e., Pct $\geq$ 80 th) and mean precipitation. However, for those middle to lower percentiles there seems to be no simple, clear correspondence with ENSO.

Annual anomalies of precipitation percentiles are computed as well for land and ocean, separately (not shown). Over tropical oceans, the changes/trends are generally consistent with those for land + ocean shown above, although with more intense variations on the interannual time scale. Over tropical land, positive trend occurs for Pct $\geq 80$ th and for Pct $\leq 30$ th, whereas negative trends are seen for the percentiles between the 40th and 70th. However, these trends over tropical land are generally weak and statistically insignificant.

The same procedures are also applied to the AMIP and CMIP5 Hist-Full precipitation outputs over tropical land + ocean (Fig. 3). Their long-term averages for various percentiles are computed for the periods of 1979-2008 and 1979-2012 (Table 2), respectively, and the differences between them and with GPCP reflect the differences in their corresponding precipitation climatologies. Annual anomalies for several selected percentiles are shown in Fig. 3. Significant positive trends exist in the 90th and 95th percentiles for both the two model-based results and GPCP. They also have positive trends in the 70th percentile, and the trends are significant for AMIP and Hist-Full. Significant downward trends are seen in the 30th percentile for GPCP and AMIP, whereas for Hist-Full the trend is not significant (the $p$ value equals 0.10). For the lower percentiles (Pct $\leq 10$ th), changes are weak and statistically insignificant (not shown). Same-sign changes/trends in the percentiles shown in Fig. 3 for both the observations and models, especially for the CMIP5 Hist-Full case, probably suggest the contribution from external forcings, specifically the anthropogenic GHG forcing, that results in tropical mean SST warming during the period (Fig. 2a; Gu et al. 2016). Relatively weaker trends for Hist-Full, specifically for the 90th, and 95th, and 30th percentiles, than for GPCP and AMIP may further suggest the likely impact of the interdecadal-scale internal variability, specifically the PDO, and suggest that the PDO shift in approximately 1998 may have pushed the precipitation statistics in the same direction as anthropogenic forcings, specifically the GHG forcing.

Annual anomalies of precipitation percentiles for AMIP and Hist-Full are also computed for land and ocean, separately, and are further compared to those for GPCP, respectively (not shown). Over tropical oceans, the changes/trends are generally consistent with those over land + ocean shown in Fig. 3 regarding the signs of those changes or trends, although there are some minor 
(a) GPCP Percentiles $\left(30^{\circ} \mathrm{N}-30^{\circ} \mathrm{S}\right.$; lond+oceon)

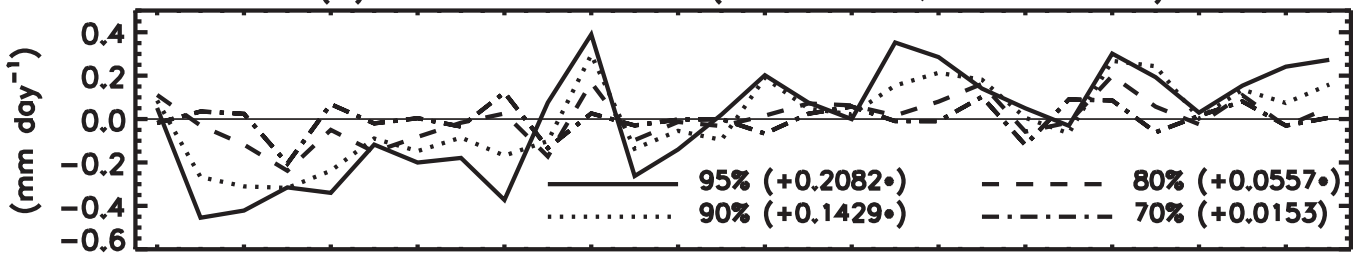

(b) GPCP Percentiles $\left(30^{\circ} \mathrm{N}-30^{\circ} \mathrm{S}\right.$; land+ocean)

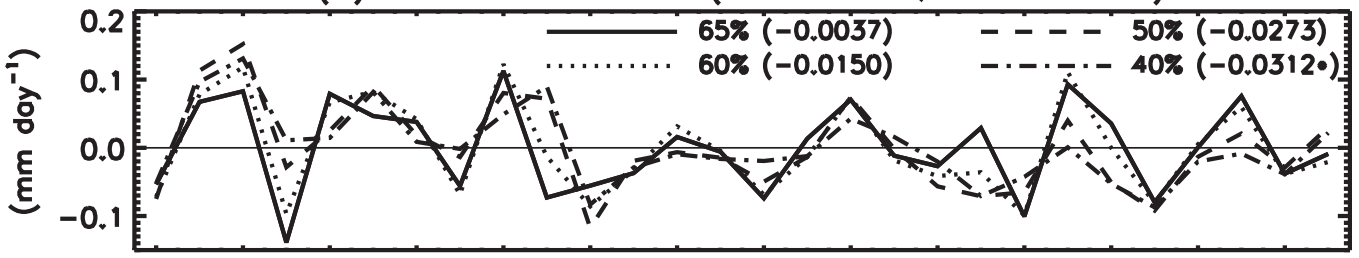

(c) GPCP Percentiles $\left(30^{\circ} \mathrm{N}-30^{\circ} \mathrm{S}\right.$; land+ocean)

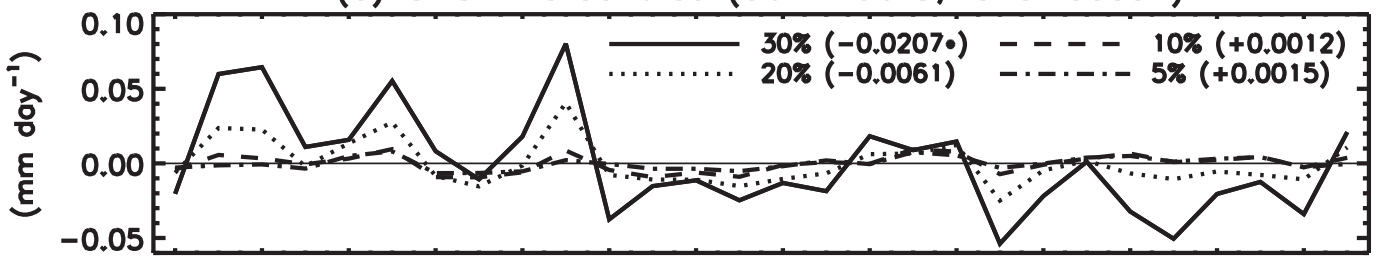

(d) GPCP mean precipitation $\left(30^{\circ} \mathrm{N}-30^{\circ} \mathrm{S}\right.$; land+ocean)

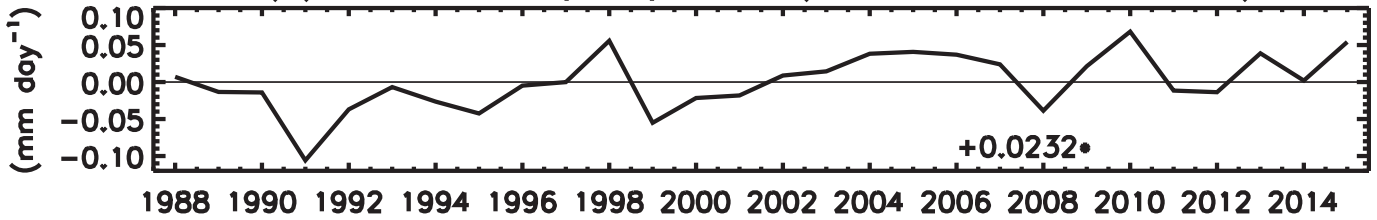

FIG. 1. Annual anomalies of (a)-(c) precipitation percentiles and (d) mean precipitation determined by GPCP monthly rain rates between $30^{\circ} \mathrm{N}$ and $30^{\circ} \mathrm{S}$. Also shown are their corresponding linear trends $\left(\mathrm{mm} \mathrm{day}^{-1} \mathrm{decade}^{-1}\right)$, and those followed by an asterisk $(*)$ are statistically significant (as defined in text).

differences in trend magnitudes. Over tropical land, positive trends can be found for all three for high percentiles (Pct $\geq 80$ th) whereas discrepancies exist for lower percentiles (Pct $\leq 10$ th). Nevertheless, as for GPCP all these changes/trends are statistically insignificant over land.

\section{Occurrence frequency of various precipitation categories}

Four precipitation categories (at each grid cell) are defined according to long-term mean monthly precipitation percentiles (Pct) at all tropical grid cells $\left(30^{\circ} \mathrm{N}-\right.$ $\left.30^{\circ} \mathrm{S}\right)$, namely Wet $[P \geq \operatorname{Pct}(70$ th $)]$, Intermediate [Pct (70th) $>P \geq \operatorname{Pct}(30$ th)], Dry [Pct(30th) $>P \geq \operatorname{Pct}$ (5th)], and No Rain $[\operatorname{Pct}(5$ th $)>P \geq \operatorname{Pct}(0$ th) $]$. For monthly GPCP during 1988-2015 (Table 2), Pct(70th) = $3.87 \mathrm{~mm} \mathrm{day}^{-1}, \operatorname{Pct}(30 \mathrm{th})=0.44 \mathrm{~mm} \mathrm{day}^{-1}$, and Pct(5th) $=$ $0.026 \mathrm{~mm} \mathrm{day}^{-1}$. The frequencies of occurrence (irrespective of months) for these four precipitation categories are then estimated (Figs. 4a-d). For comparison, the climatological mean precipitation during the same period is also depicted in Fig. 4e. High correspondence is readily seen between Wet and mean precipitation, specifically with regard to their spatial structures in the deep tropics (Figs. 4a and 4e), confirming the dominant contribution of the Wet category (or deep convective activity) to mean precipitation. The areas of Wet also roughly correspond to the global monsoon precipitation domain (e.g., Wang et al. 2012), except right along the equator and along the central-eastern Pacific ITCZ. Contributions from Intermediate to mean precipitation primarily appear along the margins of deep convective zones and in the subtropics of both hemispheres (Fig. 4b), while the Dry category is generally located as expected in the east ocean basins of the subtropics, near the western Indian Ocean-Arabian Sea, and over several land (desert) regions including North Africa and part of Australia (Fig. 4c). Very dry or No Rain grid cells are generally seen over the subtropical land deserts, especially in North Africa (Fig. 4d). 
(a) Tropical $\left(30^{\circ} \mathrm{N}-30^{\circ} \mathrm{S}\right)$ SST anomalies

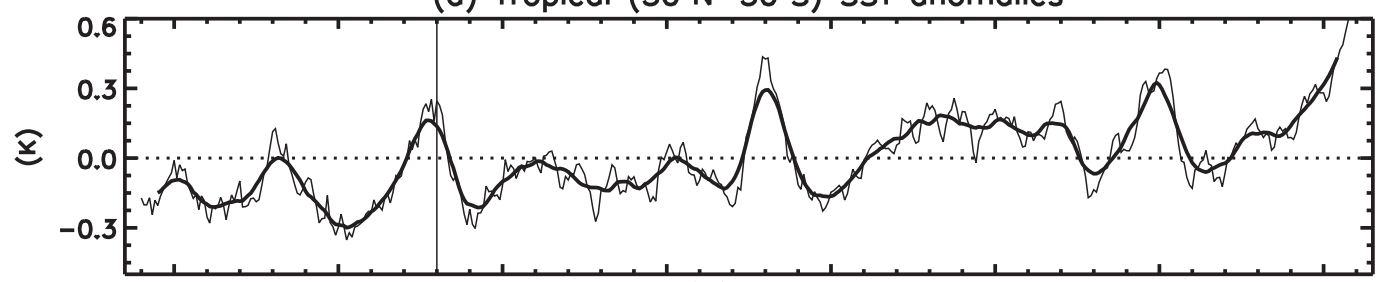

(b) PDO

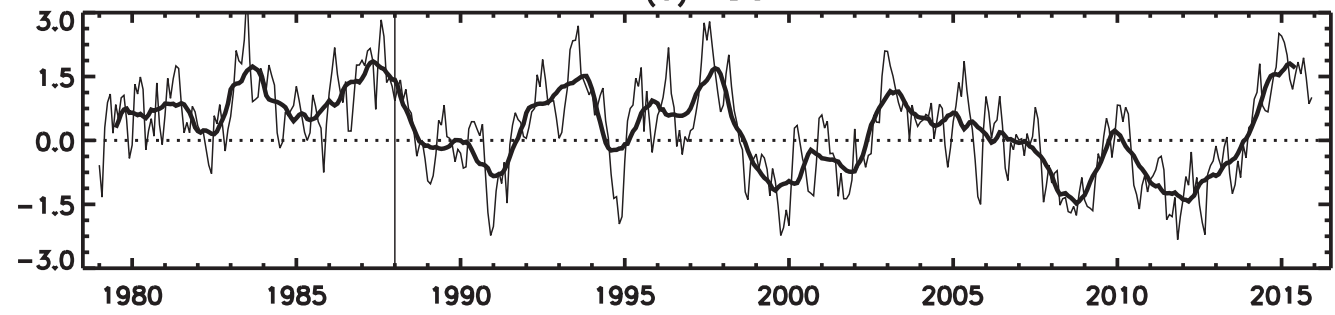

FIG. 2. Time series of (a) tropical mean SST anomalies $\left(30^{\circ} \mathrm{N}-30^{\circ} \mathrm{S}\right)$ and (b) PDO index. Thin lines represent monthly mean anomalies, and thick ones denote corresponding 13-month running means.

During the satellite era, in addition to the tropical mean SST increase likely driven primarily by the anthropogenic GHG forcing (Fig. 2a; e.g., Gu et al. 2016), interannual variations are also evident and related to the
ENSO events for high year-to-year correspondence between tropical mean SST and the ENSO index Niño-3.4 (not shown). Decadal/interdecadal-scale variability can be discerned as well, probably associated with the phase

(a) 95 Percentile $\left(30^{\circ} \mathrm{N}-30^{\circ} \mathrm{S}\right.$; land+ocean)

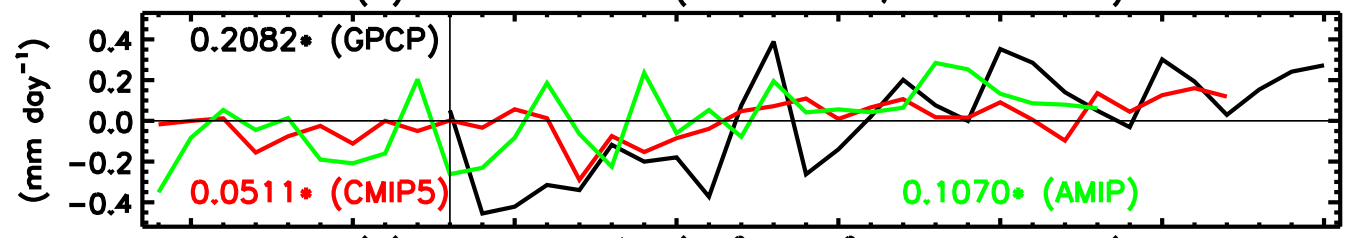

(b) 90 Percentile $\left(30^{\circ} \mathrm{N}-30^{\circ} \mathrm{S}\right.$; land+ocean)

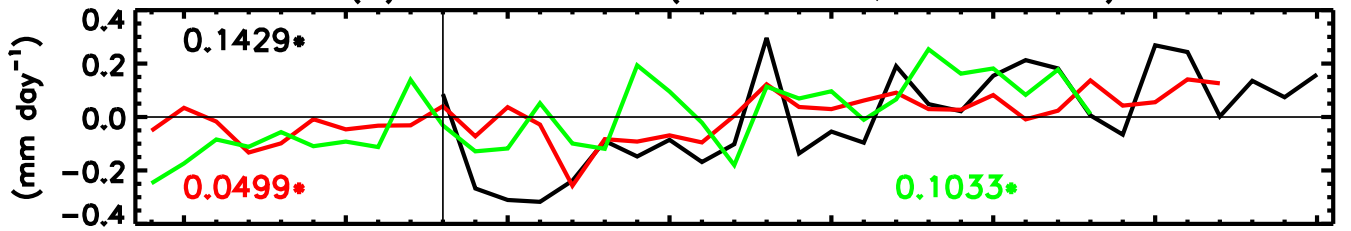

(c) 70 Percentile $\left(30^{\circ} \mathrm{N}-30^{\circ} \mathrm{S}\right.$; land+ocean)

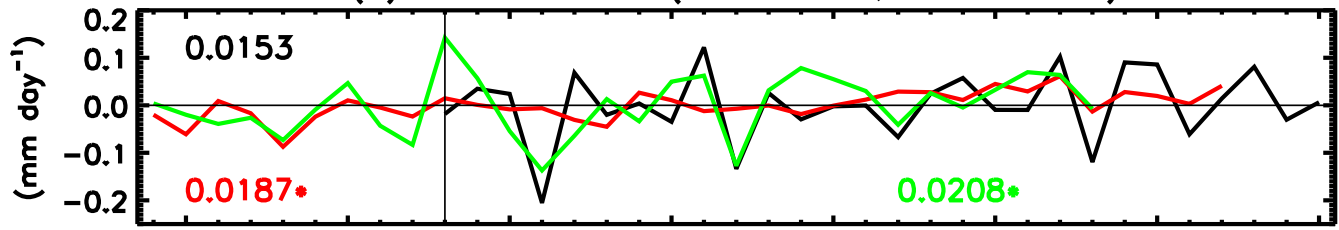

(d) 30 Percentile $\left(30^{\circ} \mathrm{N}-30^{\circ} \mathrm{S}\right.$; land+ocean)

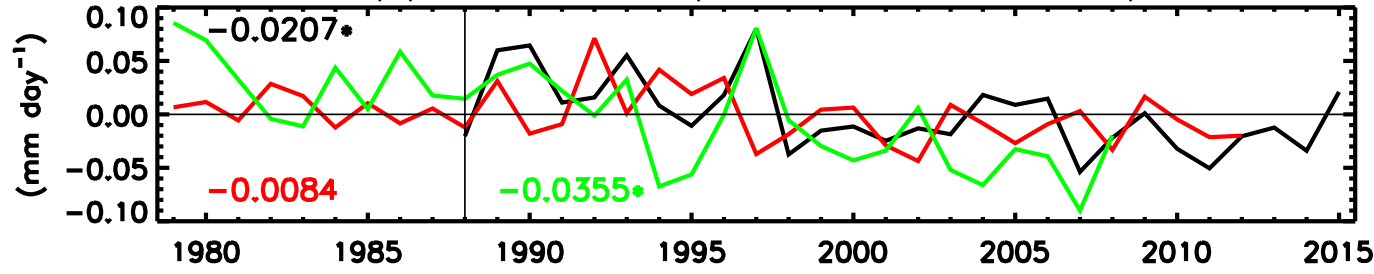

FIG. 3. Annual anomalies of the (a) 95th, (b) 90th, (c) 70th, and (d) 30th precipitation percentiles between $30^{\circ} \mathrm{N}$ and $30^{\circ} \mathrm{S}$ for GPCP (black), AMIP (green), and Hist-Full (red) monthly rain rates. Also shown are their corresponding linear trends $\left(\mathrm{mm} \mathrm{day}^{-1} \mathrm{decade}^{-1}\right)$, and those followed by an asterisk $(*)$ are statistically significant. 
(a) GPCP (Wet)

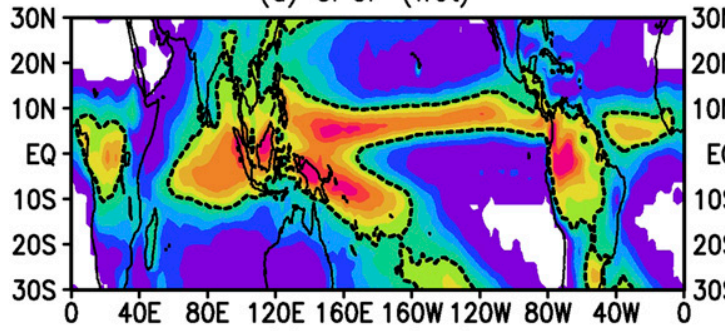

(c) GPCP (Dry)

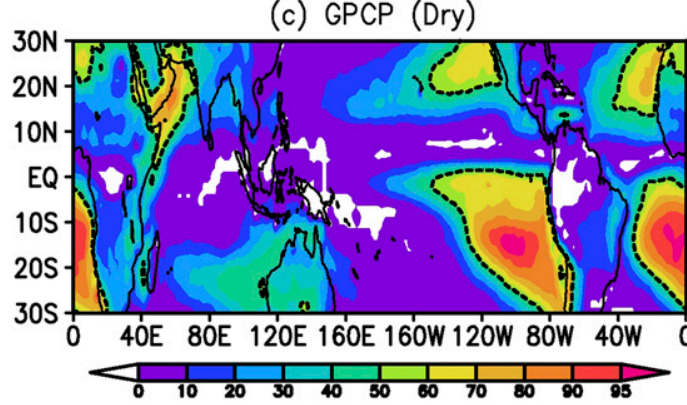

(b) GPCP (Intermediate)

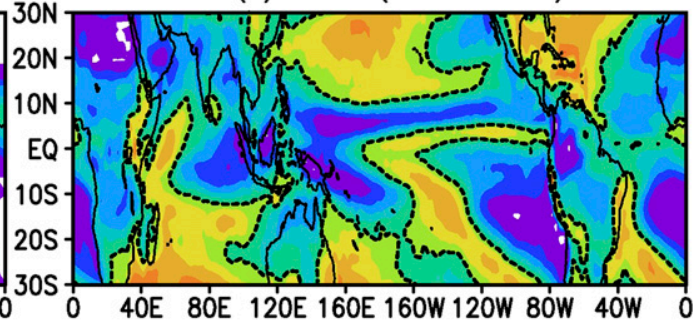

(d) GPCP (No rain)

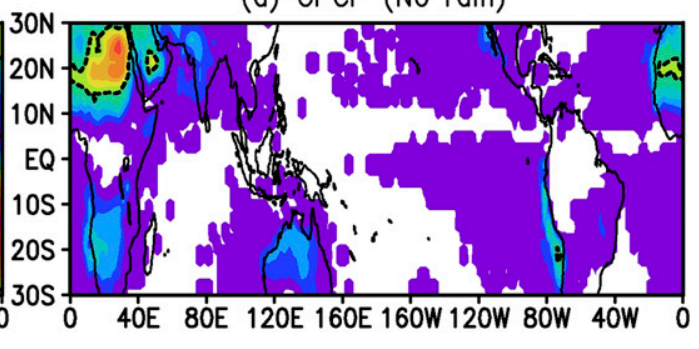

(e) GPCP mean precipitation

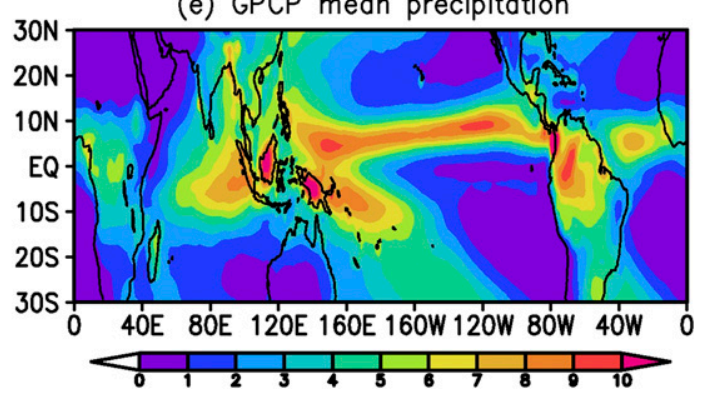

FIG. 4. Spatial distribution of occurrence frequency ( $\%$ ) for four precipitation categories stratified by monthly rain rates $\left(P ; \mathrm{mm} \mathrm{day}^{-1}\right.$ ) during 1988-2015: (a) $P \geq 3.87$ (70th percentile; Wet), (b) 3.87 $>P \geq 0.44$ (30th-70th percentile; Intermediate), (c) $0.44>P \geq 0.026$ (5th-30th percentile; Dry), and (d) $0.026>P \geq 0$ (0-5th percentile; No Rain). Black dashed contours in (a)-(d) indicate that occurrence frequency equals 50\%. (e) GPCP climatological mean rain rates $\left(\mathrm{mm} \mathrm{day}^{-1}\right)$ during 1988-2015.

shift of the PDO (Fig. 2b; e.g., Mantua and Hare 2002; Burgman et al. 2008), which might be the primary reason for the recent global mean temperature hiatus (e.g., Kosaka and Xie 2013; Trenberth and Fasullo 2013), although this temperature hiatus may have also been contributed by other mechanisms (e.g., Solomon et al. 2010; Santer et al. 2014). Thus, to examine possible changes on interdecadal/trend time scales, the occurrence frequencies of the four precipitation categories from GPCP are computed for the two subperiods: 1988-97 and 19982015. The differences (later period - earlier period) between these two subperiods are then computed to show the epoch changes for each category (Figs. 5a-d). The epoch differences in mean precipitation are also computed for comparison (Fig. 5e).

Spatial patterns of the epoch difference in mean precipitation are generally similar to those of precipitation trends at grid cells (e.g., Gu et al. 2016), indicating that epoch difference could approximately represent interdecadal/trend time scale changes during the time period. Precipitation decreases cover the central-eastern Pacific except for a narrow band of increase along the ITCZ and south of the equator. Precipitation increases are generally seen in the western Pacific and Indian Ocean. The phase shift of the PDO has been shown to be a major factor in these changes, although the anthropogenic GHG forcing may have also contributed to the long-term precipitation change/trend (e.g., Gu and Adler 2013; Gu et al. 2016). The epoch differences in the occurrence frequency for the Wet category manifest a similar spatial distribution as for mean precipitation (Figs. 5a,5e). Wet grid cells are more frequently seen in the Indian Ocean and western Pacific and along the SPCZ, and less frequently seen east of about $160^{\circ} \mathrm{E}$ except along the ITCZ and south of the equator east of about $150^{\circ} \mathrm{W}$. The occurrence frequency differences for Intermediate tend to be opposite to those for Wet in many regions, especially in the tropical central-eastern Pacific, along the SPCZ, and in the Indian Ocean and western Pacific 
(a) GPCP (Wet)

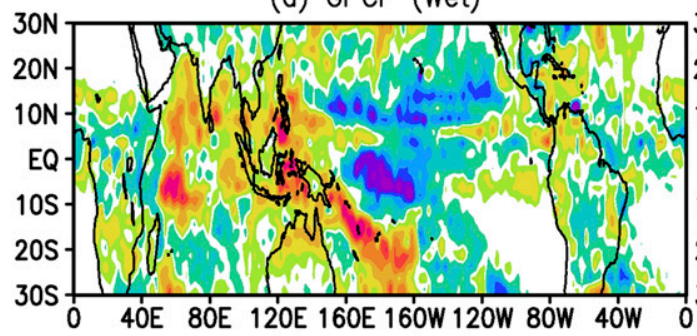

(c) GPCP (Dry)

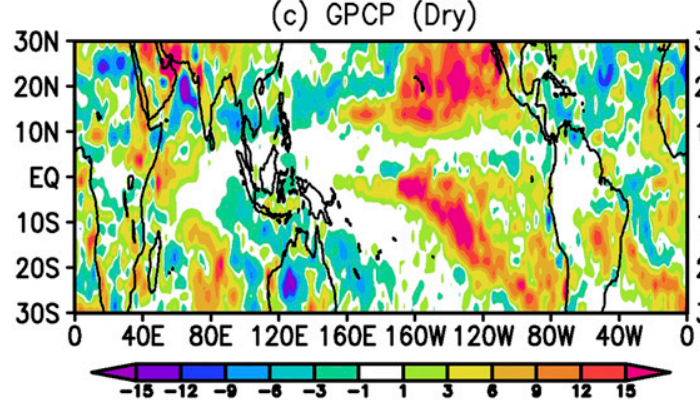

(b) GPCP (Intermediate)

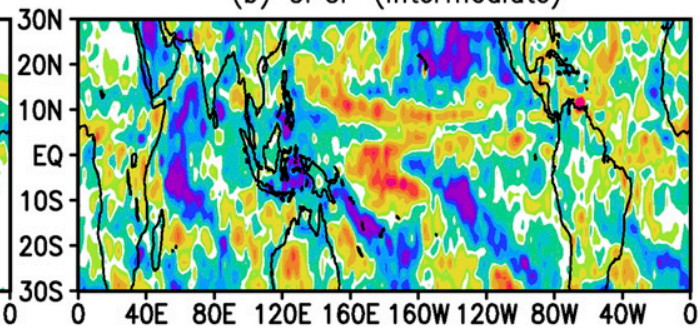

(d) GPCP (No rain)

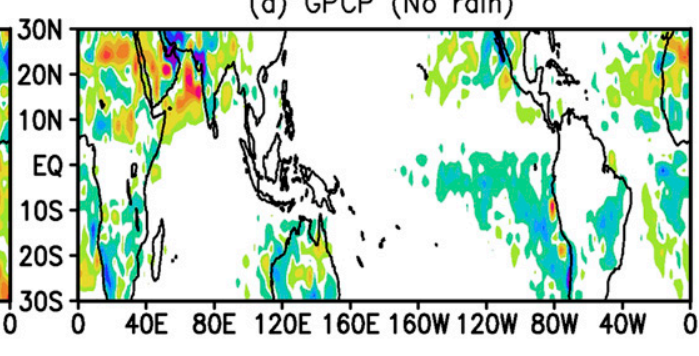

(e) Epoch difference of mean precipitation

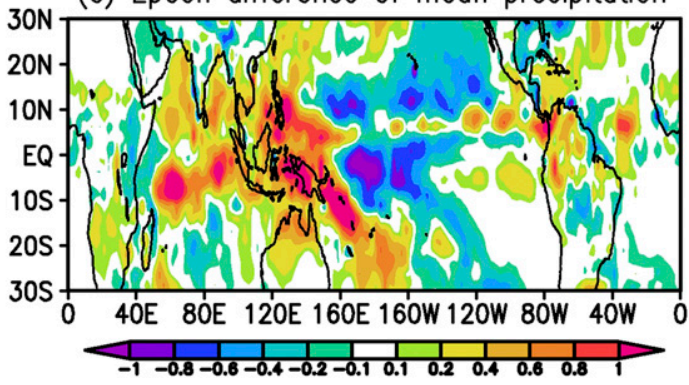

FIG. 5. Epoch differences (later period - earlier period) in occurrence frequency (\%) for four precipitation categories stratified by GPCP monthly rain rates $\left(P ; \mathrm{mm} \mathrm{day}^{-1}\right)$ between two time periods (1988-97 and 19982015): (a) $P \geq 3.87$ (70th percentile; Wet), (b) $3.87>P \geq 0.44$ (30th-70th percentile; Intermediate), (c) $0.44>P \geq$ 0.026 (5th-30th percentile; Dry), and (d) $0.026>P \geq 0$ (0-5th percentile; No Rain). (e) Epoch differences in GPCP mean precipitation ( $\mathrm{mm} \mathrm{day}^{-1}$ ) between two time periods (1988-97 and 1998-2015).

(Figs. 5a,b). There are also regions with occurrence frequency decline for both Wet and Intermediate where the occurrence frequency for Dry increases, such as over a large portion of the northeast Pacific right off the North American continent (Fig. 5c). Occurrence frequency reduction for Intermediate also occurs in the South Pacific east of the SPCZ and in the South Atlantic, generally accompanied by the increasing occurrence for the Dry category. It is also noted that the occurrence frequency for Intermediate reduces across the tropics concomitant with the expansion of dry zones following global mean temperature and tropical mean SST warming (e.g., Lu et al. 2007). Changes in the occurrence frequency for No Rain are generally weak and can only be seen in several regions including occurrence frequency increases over northern Indian Ocean and West Africa.

For AMIP and Hist-Full, similar procedures are applied to define four precipitation categories (at each grid) according to their long-term-mean monthly precipitation percentiles (Table 2). For AMIP during 1979-2008, $\operatorname{Pct}(70 \mathrm{th})=4.91 \mathrm{~mm} \mathrm{day}^{-1}, \operatorname{Pct}(30 \mathrm{th})=1.06 \mathrm{~mm} \mathrm{day}^{-1}$, and Pct $(5 \mathrm{th})=0.19 \mathrm{~mm} \mathrm{day}^{-1}$; and for CMIP5 HistFull during 1979-2012, Pct(70th) $=4.65 \mathrm{~mm} \mathrm{day}^{-1}$, $\operatorname{Pct}(30 \mathrm{th})=1.24 \mathrm{~mm} \mathrm{day}^{-1}$, and Pct $(5 \mathrm{th})=0.20 \mathrm{~mm} \mathrm{day}^{-1}$.

The epoch differences in the occurrence frequency for the four precipitation categories from AMIP are then computed using similar procedures as for Fig. 5, with a relatively shorter later subperiod for the availability of AMIP outputs: 1998-2008 (Figs. 6a-d). The epoch difference in mean precipitation is also displayed in Fig. 6e. High correspondences in these quantities between AMIP and GPCP can readily be found especially with regard to their broad spatial structures (Figs. 5 and 6), likely showing the capabilities of model simulations in reproducing the observed changes derived from GPCP. Finer-scale features are more apparent in the GPCP analysis, such as the ITCZ feature in the central/eastern Pacific seen in the change of the mean values and for the Wet category, given that the 
(a) AMIP (Wet)

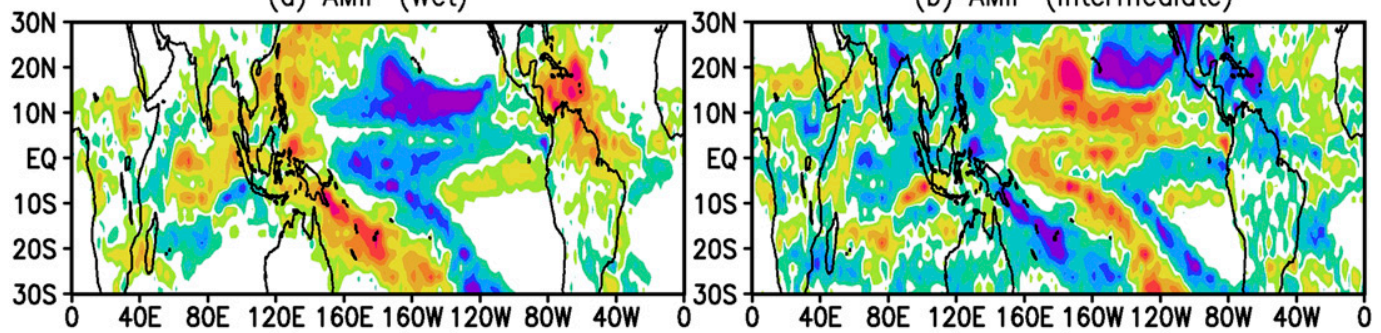

(c) AMIP (Dry)

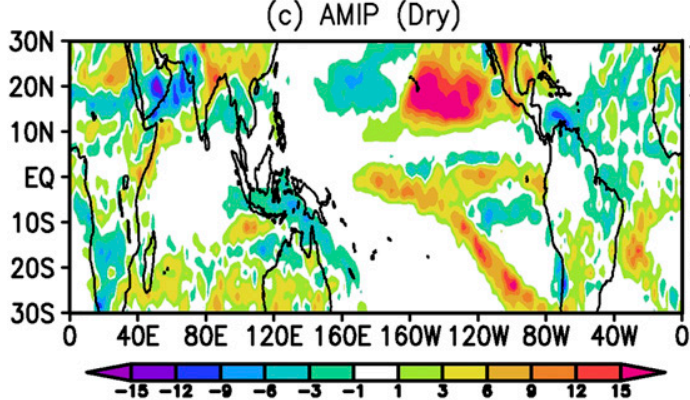

(d) AMIP (No rain)

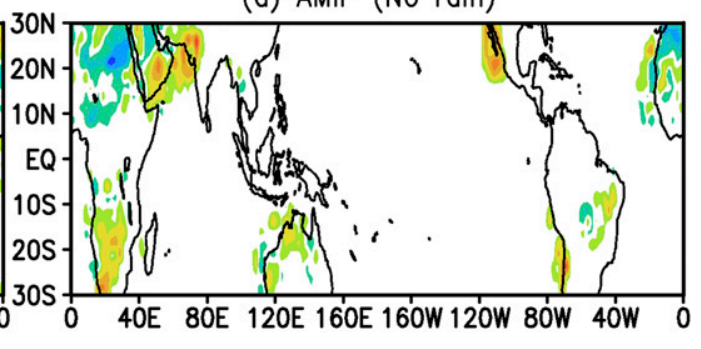

(e) Epoch difference of mean precipitation

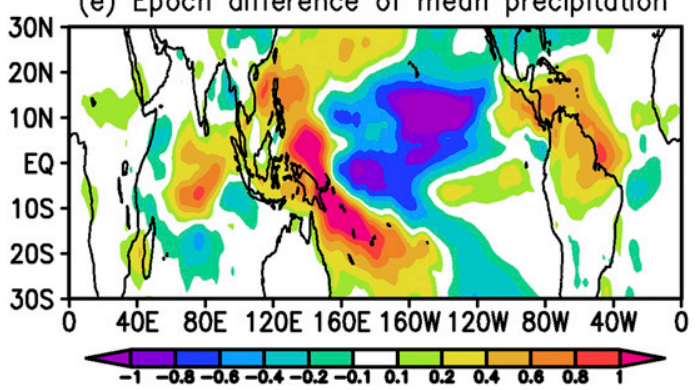

FIG. 6. Epoch differences in occurrence frequency (\%) for four precipitation categories stratified by AMIP multiensemble-mean monthly rain rates $\left(P ; \mathrm{mm}\right.$ day $\left.^{-1}\right)$ between two time periods (1988-97 and 1998-2008): (a) $P \geq$ 4.91 (70th percentile), (b) $4.91>P \geq 1.06$ (30th-70th percentile), (c) $1.06>P \geq 0.19$ (5th-30th percentile), and (d) $0.19>P \geq 0$ (0-5th percentile). (e) Epoch differences in mean precipitation $\left(\mathrm{mm} \mathrm{day}^{-1}\right)$ between two time periods (1988-97 and 1998-2008).

observed precipitation (GPCP) can only be considered as one realization.

To make a further comparison, the epoch differences in the occurrence frequency of the four precipitation categories from CMIP5 Hist-Full are estimated as well within the period of 1988-2012 (Figs. 7a-d). Different from AMIP, there are no evident, coherent spatial structures of changes for these precipitation categories. The epoch difference of mean precipitation (Fig. 7e) also manifests a different spatial pattern than that from AMIP and GPCP, and no clear correspondence can be found between mean precipitation and Wet, Intermediate, or Dry with regard to spatial structures of change. The Hist-Full results here have weaker magnitudes (note the color scale difference) than the GPCP and AMIP results. Obviously, a lack of (realistic) SST forcing related to the PDO in Hist-Full, not the discrepancies in climatological mean precipitation and occurrence frequencies of these precipitation categories between Hist-Full and both GPCP and AMIP (not shown), could primarily explain these differences. This may also confirm the likely dominant contributions of (observed) SST during the time period to these spatial features for both GPCP and AMIP shown in Figs. 5 and 6. Nevertheless, in examining the change images for the entire domain for Hist-Full, there are certain consistencies between it and either GPCP or AMIP. For instance, for Intermediate, negative anomalies tend to dominate over the domain, while more positive anomalies tend to appear over more areas for Wet, Dry, and mean precipitation. This may confirm the effect of external forcings, specifically the anthropogenic GHG forcing, in a similar way as in the discussion of Fig. 3.

\section{Variabilities/changes in precipitation intensity and areal extents of various precipitation categories}

The four climatologically distinct zones (Wet, Intermediate, Dry, and No Rain) are further determined 
(a) CMIP5 (Wet)

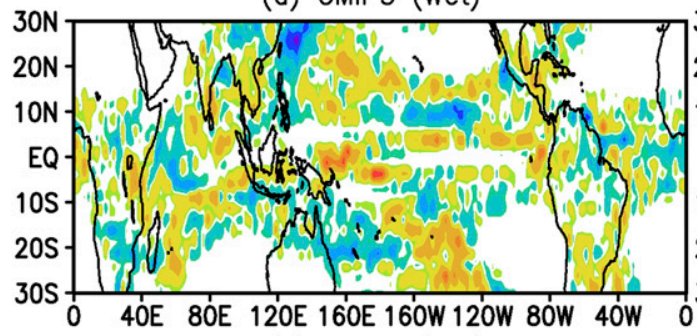

(c) CMIP5 (Dry)

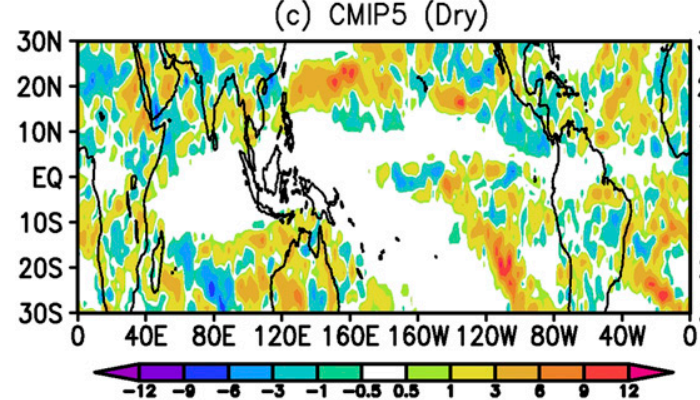

(b) CMIP5 (Intermediate)

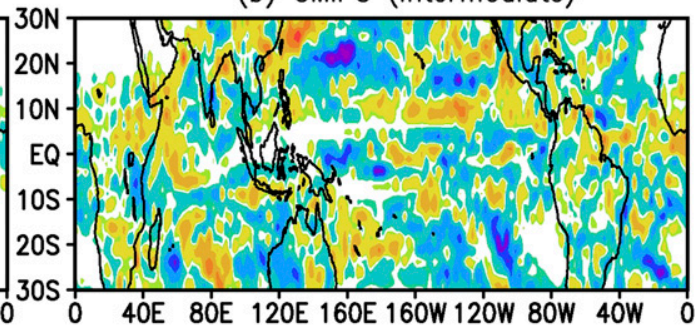

(d) CMIP5 (No rain)

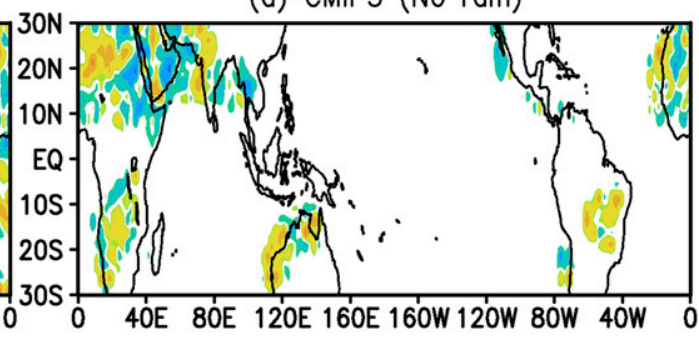

(e) Epoch difference of mean precipitation

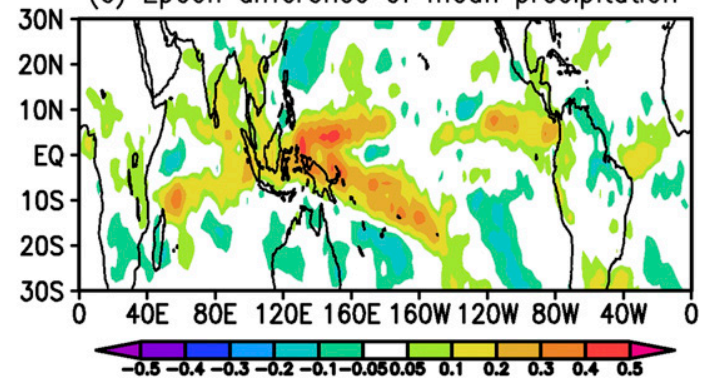

FIG. 7. Epoch differences in occurrence frequency (\%) for four precipitation categories stratified by multiensemble-mean monthly rain rates $\left(P ; \mathrm{mm} \mathrm{day}^{-1}\right)$ of CMIP5 historical full forcing simulations between two time periods (1988-97 and 1998-2012): (a) $P \geq 4.65$ (70th percentile), (b) $4.65>P \geq 1.24$ (30th-70th percentile), (c) $1.24>$ $P \geq 0.20$ (5th-30th percentile), and (d) $0.20>P \geq 0$ (0-5th percentile). (e) Epoch differences in mean precipitation $\left(\mathrm{mm}_{\text {day }}{ }^{-1}\right)$ between two time periods (1988-97 and 1998-2012).

for GPCP corresponding to the four precipitation categories defined above. Time series representing the sizes of these four zones are constructed by counting the number of grid cells for each precipitation category after considering the effect of latitude (i.e., $S_{\text {wet }}, S_{\text {inter }}, S_{\text {dry }}$, and $\left.S_{\text {norain }}\right)$. Two other time series are also constructed by area-averaging precipitation over Wet $\left(P_{\text {wet }}\right)$ and Intermediate $\left(P_{\text {inter }}\right)$ zones, in addition to the ones denoting tropical mean precipitation $\left(P_{\text {mean }}\right)$. Annualmean-anomaly time series are then estimated. Annual mean anomalies for GPCP $P_{\text {wet }}$ and $P_{\text {inter }}$ are shown in Fig. 8 for tropical land + ocean, land, and ocean. For comparison, annual mean $P_{\text {mean }}$ anomalies (same as in Fig. 1d) are also shown. Annual mean $P_{\text {wet }}$ tends to follow variations in $P_{\text {mean }}$ over tropical land + ocean, land, and ocean, but with much larger magnitudes. Both $P_{\text {wet }}$ and $P_{\text {mean }}$ have significant positive trends over tropical land + ocean; however, the trend in $P_{\text {wet }}$ is much stronger, roughly consistent with the results for higher annual percentiles (Pct $\geq 80$ th) shown in Fig. 1 . Over tropical ocean, $P_{\text {wet }}$ shows a significant positive trend, in contrast to a weaker, statistically insignificant trend in $P_{\text {mean }}$. Over tropical land, neither $P_{\text {wet }}$ nor $P_{\text {mean }}$ has a significant trend, although the trend of $P_{\text {mean }}$ trend is relatively stronger. More intense trends in $P_{\text {wet }}$ tend to suggest its stronger sensitivity to surface temperature change than $P_{\text {mean }}$. Negative trends are found in $P_{\text {inter }}$ over tropical land + ocean, land, and ocean, but none of them can achieve the significance level. The stronger $P_{\text {wet }}$ trend over ocean as compared to land may relate to the increasing availability of moisture (specific humidity) over the ocean related to increasing SST during the period. Over land the increasing moisture is guided by advection from the ocean and may be more limited.

Another way to look at these types of variation is to examine not the mean value of the rainfall in these intensity zones, but the areas of these distinct (intensity) zones. The size of the Wet zones $\left(S_{\text {wet }}\right)$ shows positive 
(a) $\operatorname{GPCP}\left(30^{\circ} \mathrm{N}-30^{\circ} \mathrm{S}\right.$; land+ocean)

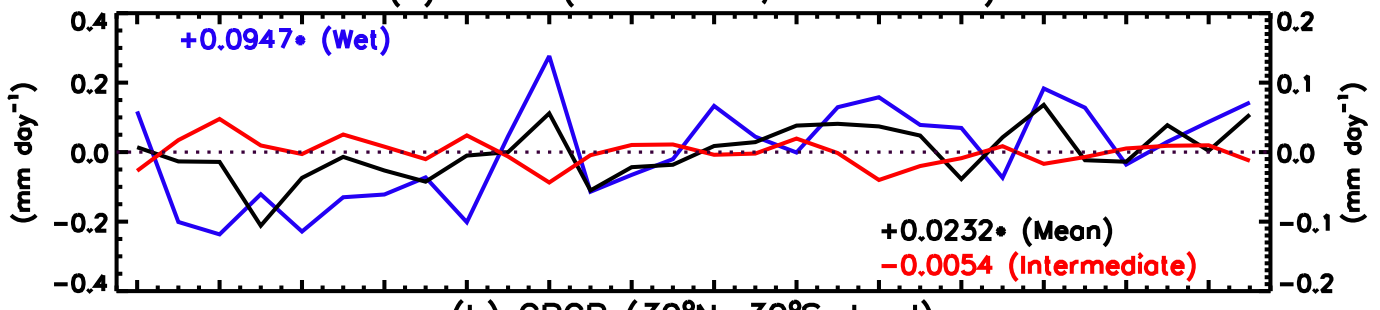

(b) GPCP $\left(30^{\circ} \mathrm{N}-30^{\circ} \mathrm{S}\right.$; land)

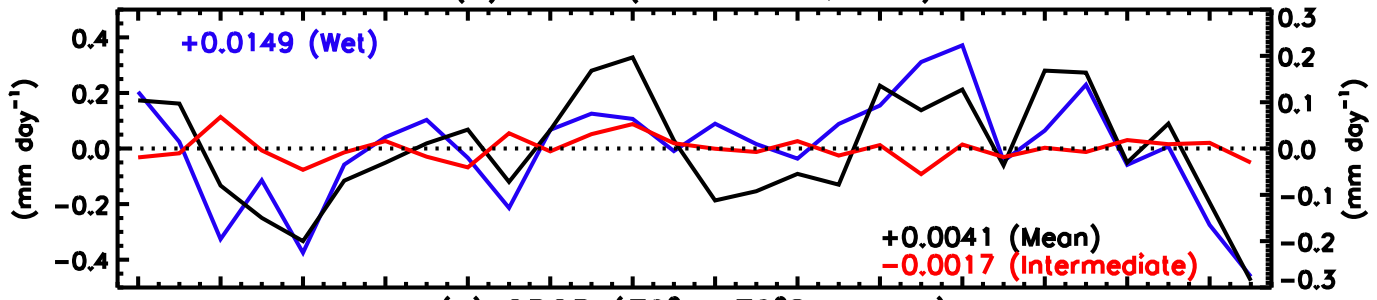

(c) GPCP $\left(30^{\circ} \mathrm{N}-30^{\circ} \mathrm{S}\right.$; ocean)

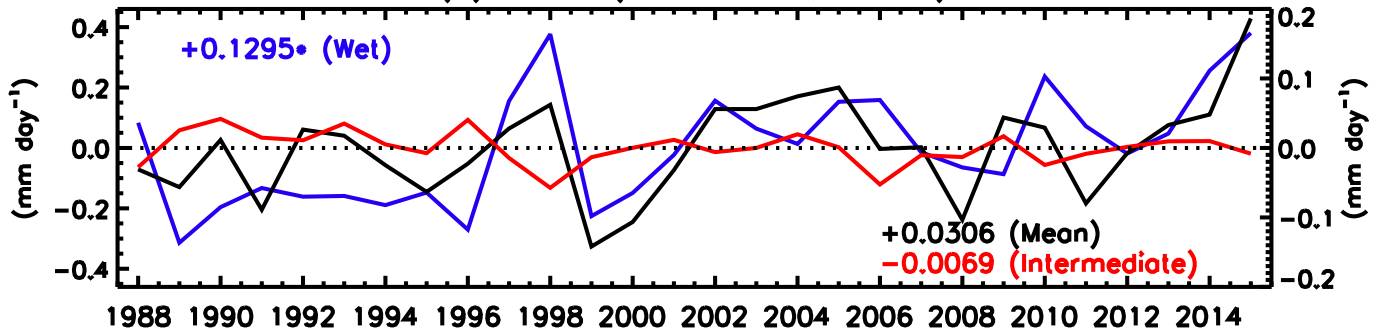

FIG. 8. Annual anomalies in tropical mean precipitation (black) and precipitation averaged over wet (blue) and intermediate rainy (red) zones between $30^{\circ} \mathrm{N}$ and $30^{\circ} \mathrm{S}$. Scales on right axes are for tropical mean precipitation and precipitation over intermediate zones. Also shown are their corresponding linear trends $\left(\mathrm{mm} \mathrm{day}^{-1} \mathrm{decade}^{-1}\right)$, and those followed by an asterisk $(*)$ are statistically significant.

trend over tropical land + ocean, land, and ocean (black in Fig. 9) but none of these trends is statistically significant, roughly in agreement with past studies (e.g., Johnson and Xie 2010; Hoyos and Webster 2012). Decreases in the size of Intermediate zones appear in the tropics consistent with Fig. 5b, even though the trend over tropical land is not statistically significant (red in Fig. 9). Furthermore, there are significant increases in the Dry zones across the tropics generally confirming Fig. 5c. The No Rain zones tend to contract, even though the corresponding trends are weak and cannot reach the significance level. So, while the mean precipitation value in the Wet zone tends to increase significantly during the period, the change in area of that zone is weak. However, the decrease of the Intermediate area and the increase in the Dry zone area is more dramatic than the mean rain values in those zones. Therefore, monitoring mean precipitation in Wet zones and monitoring areas in Intermediate and Dry zones may be a more effective monitoring strategy to detect and quantify precipitation trends.

Annual mean time series from AMIP outputs are estimated as well for these variables, including tropical mean precipitation, precipitation intensity over tropical Wet and Intermediate zones, and the sizes of the four precipitation zones (Figs. 10 and 11). Similar annual mean time series from CMIP5 historical full (Hist-Full) forcing simulations are also computed using their own precipitation percentiles (Table 2) and for a different time period: 1979-2012. Significant positive trends exist in tropical mean precipitation $\left(P_{\text {mean }}\right)$ and precipitation $\left(P_{\text {wet }}\right)$ over tropical Wet zones (land+ocean) for both AMIP and Hist-Full, although their trend values tend to be smaller than those from GPCP (Figs. 10a and 10b). However, all three have much larger trends in $P_{\text {wet }}$ than in $P_{\text {mean }}$, implying that precipitation (intensity) over Wet zones becomes more intense as suggested in past studies (e.g., Held and Soden 2006), again indicating that precipitation intensity changes over Wet zones might be more appropriate for monitoring the long-term changes in the hydrological cycle for relatively higher sensitivities to surface temperature. However, monthly precipitation anomalies over tropical Wet zones have a relatively weaker correlation relation with ENSO than tropical mean precipitation anomalies (not shown), likely suggesting a different sensitivity with surface 
(a) $\operatorname{GPCP}\left(30^{\circ} \mathrm{N}-30^{\circ} \mathrm{S}\right.$; land+ocean)

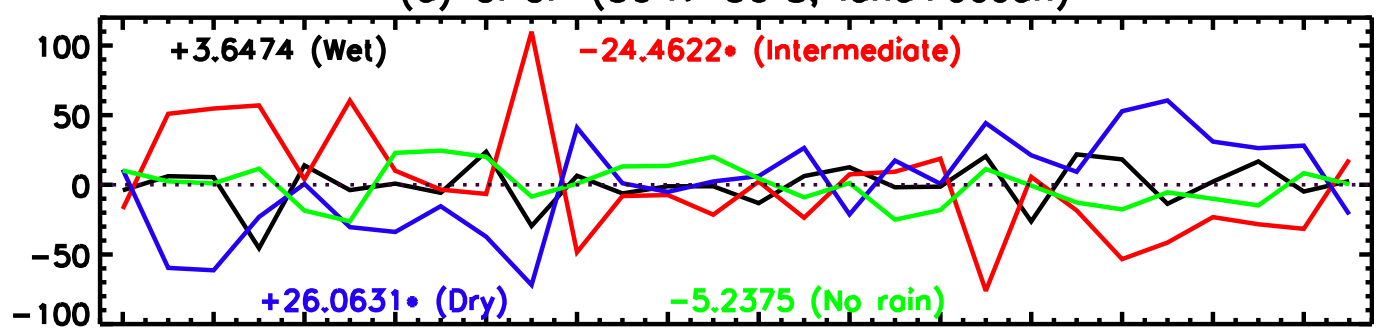

(b) GPCP $\left(30^{\circ} \mathrm{N}-30^{\circ} \mathrm{S}\right.$; land)

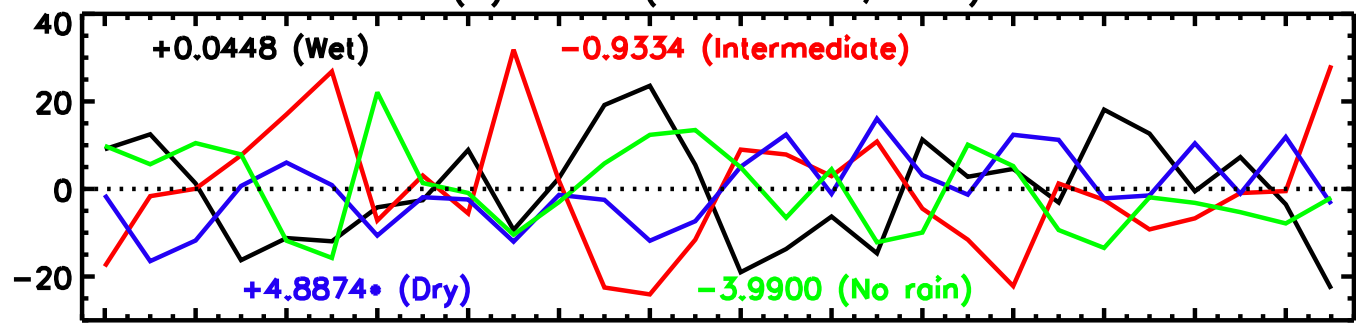

(c) GPCP $\left(30^{\circ} \mathrm{N}-30^{\circ} \mathrm{S}\right.$; ocean)

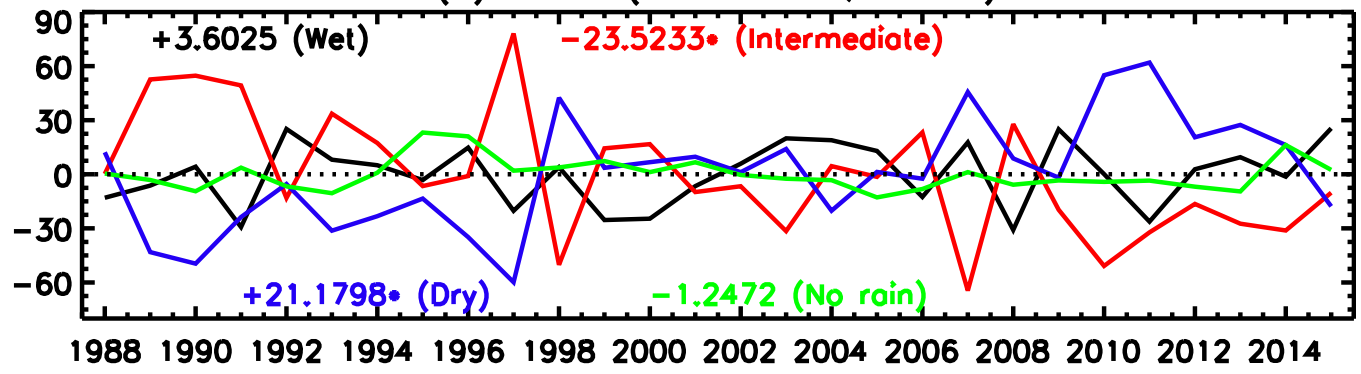

FIG. 9. Annual anomalies of pseudoareas for wet (black), intermediate rainy (red), dry (blue), and no-rain (green) zones between $30^{\circ} \mathrm{N}$ and $30^{\circ} \mathrm{S}$. The numbers are corresponding linear trends (number of pseudogrid cells per decade), and those followed by an asterisk (*) are statistically significant.

temperature on the interannual time scale that warrants further exploration. For precipitation over tropical Intermediate zones (Fig. 10c), negative trends appear in both AMIP and Hist-Full, but they are weak and cannot reach the significance level just as in GPCP.

Annual mean time series for the sizes of the four precipitation zones in the tropics (land+ocean) are depicted in Fig. 11. Similar to GPCP, significant size changes in tropical Intermediate $\left(S_{\text {inter }}\right)$ and Dry $\left(S_{\text {dry }}\right)$ zones appear for both AMIP and Hist-Full, and the trend values for AMIP are comparable to those from GPCP. Nevertheless, the trend magnitudes for Hist-Full are much smaller probably because external forcings, specifically the anthropogenic GHG forcing, are the dominant and only main contributor, while the interdecadal (internal) signal specifically the PDO phase shift is also present for GPCP and AMIP, which has the same direction of impact during the time period. This tends to further confirm that interdecadal/trend time scale changes in GPCP and AMIP are also contributed to by the internal variability including the PDO and the anthropogenic GHG forcing during the satellite era (e.g., Gu et al. 2016). For Wet zones $\left(S_{\text {wet }}\right)$, AMIP and Hist-Full have positive trends of the same order as GPCP, although the trend for Hist-Full is the only one to reach the significance threshold. The size changes for No Rain zones $\left(S_{\text {norain }}\right)$ are weak and corresponding trends are not significant for both AMIP and HistFull, similar to those for GPCP. Consistent, significant changes in $S_{\text {inter }}$ (negative trend) and $S_{\text {dry }}$ (positive trend) exist in GPCP, AMIP, and Hist-Full, suggesting that these two components could also be good indicators of decadal/trend time scale changes in the tropical hydrological cycle.

\section{Summary and concluding remarks}

Precipitation variations and changes in the tropics $\left(30^{\circ} \mathrm{N}-30^{\circ} \mathrm{S}\right)$ specifically on the interdecadal/trend time scale are examined using the satellite-based monthly precipitation product from the Global Precipitation Climatology Project (GPCP) for the post-1988 period 
(a) Annual mean precipitation $\left(30^{\circ} \mathrm{N}-30^{\circ} \mathrm{S}\right.$; land+ocean)

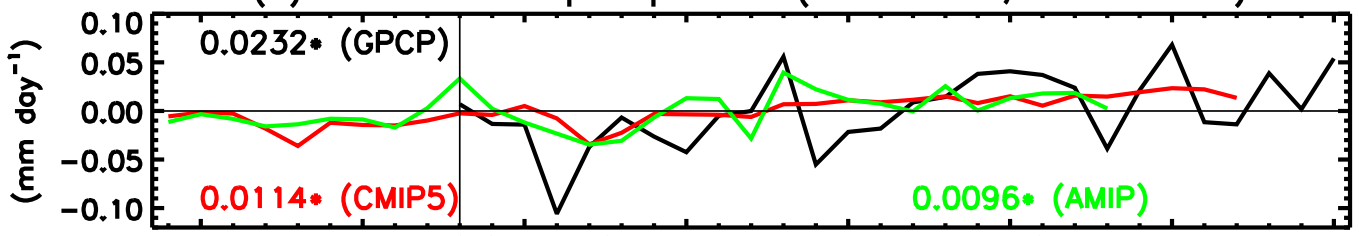

(b) Wet $\left(30^{\circ} \mathrm{N}-30^{\circ} \mathrm{S}\right.$; land+ocean)

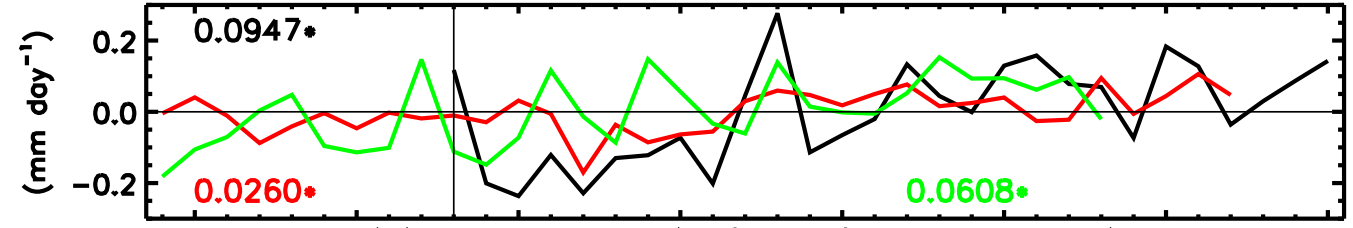

(c) Intermediate $\left(30^{\circ} \mathrm{N}-30^{\circ} \mathrm{S}\right.$; lond+oceon)

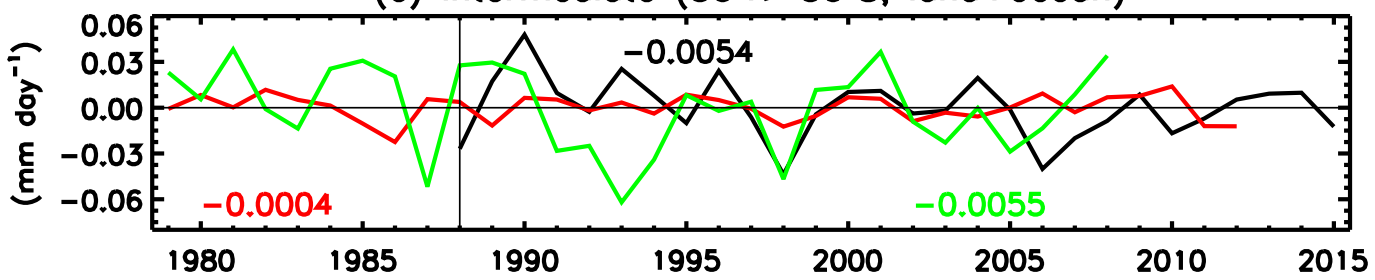

FIG. 10. Annual anomalies in (a) tropical mean precipitation and precipitation averaged over (b) wet and (c) intermediate rainy zones between $30^{\circ} \mathrm{N}$ and $30^{\circ} \mathrm{S}$ for GPCP (black), AMIP (green), and Hist-Full (red) monthly rain rates. Also shown are their corresponding linear trends $\left(\mathrm{mm} \mathrm{day}^{-1} \mathrm{decade}^{-1}\right)$, and those followed by an asterisk $(*)$ are statistically significant.

and also calculations of monthly precipitation from ensembles of AMIP and CMIP models. Instead of focusing only on mean precipitation amount, variations and changes in monthly precipitation intensity parameters are examined. These parameters include percentiles, mean precipitation in zones defined as Wet and Intermediate, and also the areas of four distinct zones that have not been explicitly examined in past studies. The relative roles of interdecadal (PDO) shift and implied external forcings, specifically anthropogenic greenhouse gas (GHG) forcing, are interpreted by comparing the GPCP observations, AMIP results forced by observed SST, and CMIP Hist-Full runs (no realistic PDO effect).

Percentiles in the monthly GPCP for land and ocean combined show a positive trend for the upper one-third of the percentiles (Pct $\geq 70$ th), with the trends for Pct $\geq$ 80th being significant. Negative trends (significant) appear for the 30th-40th percentiles, although downward trends can be found roughly for the (wider) middle onehalf percentiles (20th-65th). For the lower percentiles (Pct $\leq 10$ th), positive trends are seen, but they are weak and cannot reach the significance level. AMIP results agree strongly with those from the GPCP data in terms of the sign of the changes/trends for high and intermediate percentiles (positive and negative, respectively). The CMIP Hist-Full results also agree in the sign of the trends, but the trends are weaker. A shift is also noted in the time series around 1998, probably related to the PDO phase change at about that time.

Precipitation intensity variations and changes are also explored over the two distinct rainy zones classified by long-term monthly precipitation percentiles (Pct): Wet (Pct $\geq 70$ th) and Intermediate (70th $>$ Pct $\geq 30$ th). Temporal variations in the sizes of these two zones and the two other ones identified as Dry (30th $>$ Pct $\geq 5$ th) and No Rain (5th $>$ Pct $\geq 0$ th) are further examined. The spatial changes during the period are examined via the differences in the occurrence frequency of the four precipitation categories between the two time periods: 1988-97 and 1998-2015 (roughly aligned with the PDO phase shift) for GPCP. The results confirm intense changes on the interdecadal/trend time scale during the satellite era with the features reflecting the impact of the PDO in combination with the possible effect of external forcings, specifically the anthropogenic GHG forcing, in agreement with past studies (e.g., Gu and Adler 2013; $\mathrm{Gu}$ et al. 2016). Very similar patterns of change between the two epochs are evident in both the GPCP and AMIP results.

Precipitation intensity over the Wet zones shows much more intense change (positive) than mean precipitation does, including a more prominent decadalscale shift around 1998. For precipitation intensity over the Intermediate zones, even though decadal-scale 
(a) Wet $\left(30^{\circ} \mathrm{N}-30^{\circ} \mathrm{S}\right.$; land+ocean)

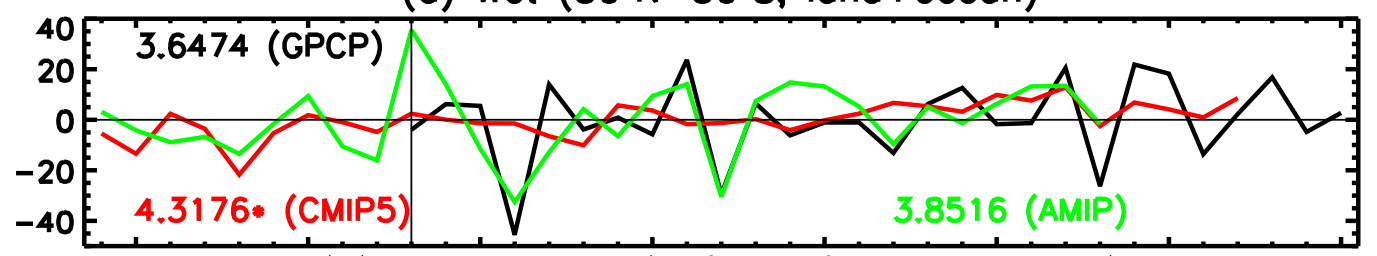

(b) Intermediate $\left(30^{\circ} \mathrm{N}-30^{\circ} \mathrm{S}\right.$; land +ocean)

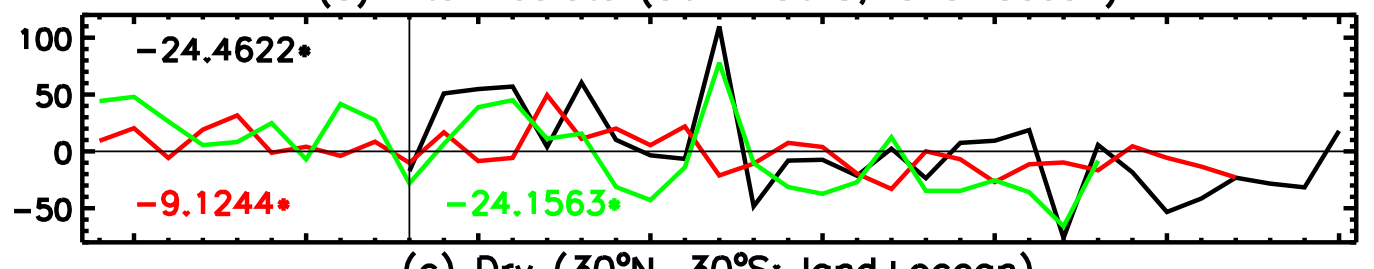

(c) $\operatorname{Dry}\left(30^{\circ} \mathrm{N}-30^{\circ} \mathrm{S}\right.$; land+ocean)

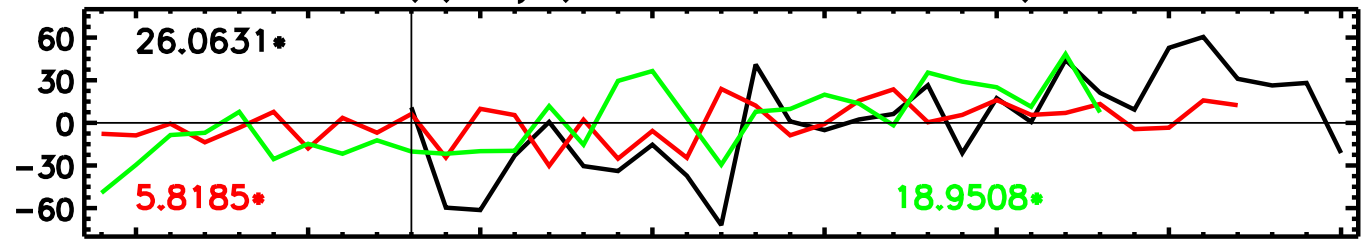

(d) No Roin $\left(30^{\circ} \mathrm{N}-30^{\circ} \mathrm{S}\right.$; land+oceon)

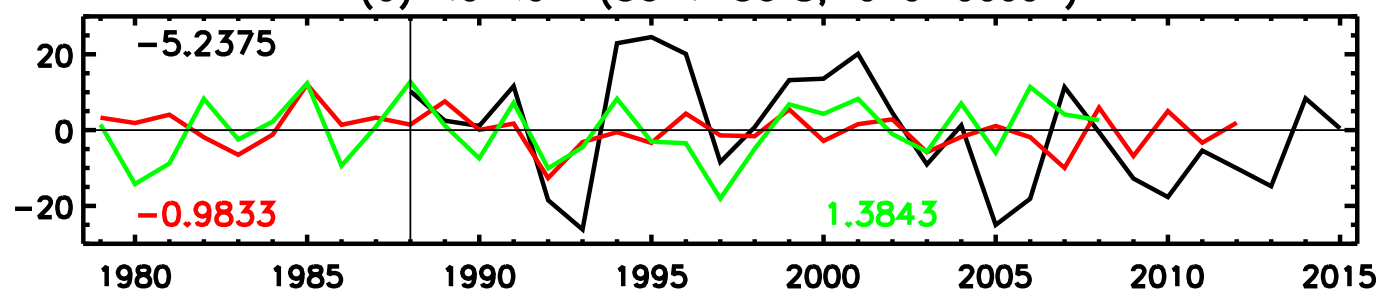

FIG. 11. Annual anomalies of pseudoareas for (a) wet, (b) intermediate rainy, (c) dry, and (d) no-rain zones between $30^{\circ} \mathrm{N}$ and $30^{\circ} \mathrm{S}$ for GPCP (black), AMIP (green), and Hist-Full (red) monthly rain rates. The numbers are corresponding linear trends (number of pseudogrid cells per decade), and those followed by an asterisk $(*)$ are statistically significant.

change is in general weak, a moderate reduction is still discernible. Furthermore, an evident decadal-scale shift appears around 1998 in the sizes of Intermediate (decreasing) and Dry (increasing) zones especially over tropical ocean and both variables $\left(S_{\text {Inter }}\right.$ and $\left.S_{\text {Dry }}\right)$ have significant trends, despite the signs of their variability/ trend being opposite. However, interdecadal-scale changes/trends in the sizes of Wet and No Rain zones are in general weak. The increasing precipitation intensity in the Wet zone is generally duplicated by the models (both AMIP and CMIP), further suggesting the effect of anthropogenic GHG forcing, and may also be a more suitable parameter for monitoring the high end of precipitation magnitude. For the Intermediate and Dry zones, stronger results are evident for the area trends and this is the case for the observations and the models. The weak change/trend in the size of tropical oceanic Wet zones $\left(S_{\text {wet }}\right)$ tends to be consistent with past studies (e.g., Johnson and Xie 2010; Hoyos and Webster 2012).
Using this relatively short time period, which is affected by both an interdecadal signal plus various external forcings, specifically the long-term GW signal, and examining intensity parameters at the monthly scale with the GPCP observations and the AMIP and CMIP models leads to a few interpretations. However, possible errors in both the models and with the observations could affect the level of confidence in the conclusions. First of all, high precipitation percentiles in the tropics and the mean precipitation in regionally wet areas (with temporally varying geographic locations) are increasing (wet getting wetter). Intermediate percentiles and areas of moderate or intermediate rainfall are decreasing. Dry areas are increasing. The strength of the signals seems to be larger over oceans. Results comparing the CMIP Hist-Full results (no realistic PDO effect even for any individual runs) to AMIP results and the observations imply that the precipitation intensity signal being observed may be a combination of the effect of anthropogenic 
GHG forcing and interdecadal (internal) variability (PDO). Obviously, additional analysis of a longer time period is needed to examine the limited observations in combination with models to understand the relations more fully. Also, a further detection and attribution analysis, which can provide more detailed estimations of the contributions from internal variability and external forcings, specifically the anthropogenic GHG forcing, may be necessary, although efforts have been made along this direction on mean precipitation changes in past studies (e.g., Zhang et al. 2007; Marvel and Bonfils 2013; Sarojini et al. 2016).

Acknowledgments. The ERSST dataset (v3b) used to estimate tropical mean SST anomalies and Nino-3.4 was downloaded from the NOAA/NCDC website at https:// www1.ncdc.noaa.gov/pub/data/cmb/ersst/v3b//. The monthly precipitation outputs of AMIP and historical full forcings simulations from multiple CMIP5 models were downloaded from the CMIP5 website (https://esgfnode.llnl.gov/search/cmip5/). We acknowledge the World Climate Research Programme's Working Group on Coupled Modelling and the U.S. Department of Energy's Program for Climate Model Diagnosis and Intercomparison. This work is supported under the NASA Energy and Water-cycle Study (NEWS) and the NASA Modeling, Analysis, and Prediction (MAP) Program.

\section{REFERENCES}

Adler, R. F., and Coauthors, 2003: The version 2 Global Precipitation Climatology Project (GPCP) monthly precipitation analysis (1979-present). J. Hydrometeor., 4, 1147-1167, https:// doi.org/10.1175/1525-7541(2003)004<1147:TVGPCP > 2.0.CO;2.

_ , G. Gu, J.-J. Wang, G. J. Huffman, S. Curtis, and D. Bolvin, 2008: Relationships between global precipitation and surface temperature on interannual and longer timescales (19792006). J. Geophys. Res., 113, D22104, https://doi.org/10.1029/ 2008JD010536.

- - - M. Sapiano, J.-J. Wang, and G. J. Huffman, 2017: Global precipitation: Means, variations and trends during the satellite era (1979-2014). Surv. Geophys., 38, 679-699, https:// doi.org/10.1007/s10712-017-9416-4.

Allan, R. P., and B. J. Soden, 2008: Atmospheric warming and the amplification of precipitation extremes. Science, 321, 14811484, https://doi.org/10.1126/science.1160787.

,-- , V. O. John, W. Ingram, and P. Good, 2010: Current changes in tropical precipitation. Environ. Res. Lett., 5, 025205, https://doi.org/10.1088/1748-9326/5/2/025205.

_ , C. Liu, M. Zahn, D. A. Lavers, E. Koukouvagias, and A. Bodas-Salcedo, 2014: Physically consistent responses of the global atmospheric hydrological cycle in models and observations. Surv. Geophys., 35, 533-552, https://doi.org/10.1007/ s10712-012-9213-Z

Allen, M. R., and W. J. Ingram, 2002: Constraints on future changes in climate and the hydrologic cycle. Nature, 419, 224-232, https://doi.org/10.1038/nature01092.
Burgman, R. J., A. C. Clement, C. M. Mitas, J. Chen, and K. Esslinger, 2008: Evidence for atmospheric variability over the Pacific on decadal timescales. Geophys. Res. Lett., 35, L01704, https://doi.org/10.1029/2007GL031830.

Garfinkel, C. I., D. W. Waugh, and L. M. Polvani, 2015: Recent Hadley cell expansion: The role of internal atmospheric variability in reconciling modeled and observed trends. Geophys. Res. Lett., 42, 10824-10831, https://doi.org/10.1002/ 2015GL066942.

Gu, G., and R. F. Adler, 2013: Interdecadal variability/long-term changes in global precipitation patterns during the past three decades: Global warming and/or Pacific decadal variability? Climate Dyn., 40, 3009-3022, https://doi.org/10.1007/ s00382-012-1443-8.

- - - G. J. Huffman, and S. Curtis, 2007: Tropical rainfall variability on interannual-to-interdecadal and longer time scales derived from the GPCP monthly product. J. Climate, 20, 4033-4046, https://doi.org/10.1175/JCLI4227.1.

,-- , and $\longrightarrow, 2016$ : Long-term changes/trends in surface temperature and precipitation during the satellite era (19792012). Climate Dyn., 46, 1091-1105, https://doi.org/10.1007/ s00382-015-2634-x.

Held, I. M., and B. J. Soden, 2006: Robust responses of the hydrological cycle to global warming. J. Climate, 19, 5686-5699, https://doi.org/10.1175/JCLI3990.1.

Hoyos, C. D., and P. J. Webster, 2012: Evolution and modulation of tropical heating from the Last Glacial Maximum through the twenty-first century. Climate Dyn., 38, 1501-1519, https:// doi.org/10.1007/s00382-011-1181-3.

Huffman, G. J., R. F. Adler, D. T. Bolvin, and G. Gu, 2009: Improving the global precipitation record: GPCP version 2.1. Geophys. Res. Lett., 36, L17808, https://doi.org/10.1029/2009GL040000.

John, V. O., R. P. Allan, and B. J. Soden, 2009: How robust are observed and simulated precipitation responses to tropical ocean warming? Geophys. Res. Lett., 36, L14702, https://doi.org/ 10.1029/2009GL038276.

Johnson, N. C., and S.-P. Xie, 2010: Changes in the sea surface temperature threshold for tropical convection. Nat. Geosci., 3, 842-845, https://doi.org/10.1038/ngeo1008.

Kosaka, Y., and S.-P. Xie, 2013: Recent global-warming hiatus tied to equatorial Pacific surface cooling. Nature, 501, 403-407, https://doi.org/10.1038/nature12534.

Lau, K.-M., and H.-T. Wu, 2007: Detecting trends in tropical rainfall characteristics, 1979-2003. Int. J. Climatol., 27, 979988, https://doi.org/10.1002/joc.1454.

Liu, C., and R. P. Allan, 2013: Observed and simulated precipitation responses in wet and dry regions: 1850-2100. Environ. Res. Lett., 8, 034002, https://doi.org.10.1088/1748-9326/8/3/034002.

— _ — , and G. J. Huffman, 2012: Co-variation of temperature and precipitation in CMIP5 models and satellite observations. Geophys. Res. Lett., 39, L13803, https://doi.org/10.1029/ 2012GL052093.

Lu, J., G. A. Vecchi, and T. Reichler, 2007: Expansion of the Hadley cell under global warming. Geophys. Res. Lett., 34, L06805, https://doi.org/10.1029/2006GL028443.

Mantua, N. J., and S. R. Hare, 2002: The Pacific decadal oscillation. J. Oceanogr., 58, 35-44, https://doi.org/10.1023/A:1015820616384.

Marvel, K., and C. Bonfils, 2013: Identifying external influences on global precipitation. Proc. Natl. Acad. Sci. USA, 110, 1930119306, https://doi.org/10.1073/pnas.1314382110.

Newman, M., and Coauthors, 2016: The Pacific decadal oscillation, revisited. J. Climate, 29, 4399-4427, https://doi.org/10.1175/ JCLI-D-15-0508.1. 
Polson, D., and G. C. Hegerl, 2016: Strengthening contrast between precipitation in tropical wet and dry regions. Geophys. Res. Lett., 43, 365-373, https://doi.org/10.1002/2016GL071194.

,$- \ldots$, R. P. Allan, and B. B. Sarojini, 2013: Have greenhouse gases intensified the contrast between wet and dry regions? Geophys. Res. Lett., 40, 4783-4787, https://doi.org/10.1002/ grl.50923.

Santer, B. D., and Coauthors, 2014: Volcanic contribution to decadal changes in tropospheric temperature. Nat. Geosci., 7, 185-189, https://doi.org/10.1038/ngeo2098.

Sarojini, B. B., P. A. Stott, and E. Black, 2016: Detection and attribution of human influence on regional precipitation. Nat. Climate Change, 6, 669-675, https://doi.org/10.1038/nclimate2976.

Seager, R., and N. Naik, 2012: A mechanisms-based approach to detecting recent anthropogenic hydroclimate change. J. Climate, 25, 236-261, https://doi.org/10.1175/JCLI-D-11-00056.1.

, - _ and G. A. Vecchi, 2010: Thermodynamic and dynamic mechanisms for large-scale changes in the hydrological cycle in response to global warming. J. Climate, 23, 4651-4668, https://doi.org/10.1175/2010JCLI3655.1.

Smith, T. M., R. W. Reynolds, T. C. Peterson, and J. Lawrimore, 2008: Improvements to NOAA's historical merged landocean surface temperature analysis (1880-2006). J. Climate, 21, 2283-2296, https://doi.org/10.1175/2007JCLI2100.1.
Solomon, S., K. H. Rosenlof, R. W. Portmann, J. S. Daniel, S. M. Davis, T. J. Sanford, and G.-K. Plattner, 2010: Contributions of stratospheric water vapor to decadal changes in the rate of global warming. Science, 327, 1219-1223, https:/doi.org/10.1126/ science.1182488.

Taylor, K. E., R. J. Stouffer, and G. A. Meehl, 2012: An overview of CMIP5 and the experiment design. Bull. Amer. Meteor. Soc., 93, 485-498, https://doi.org/10.1175/BAMS-D-11-00094.1.

Trenberth, K. E., and J. T. Fasullo, 2013: An apparent hiatus in global warming? Earth's Future, 1, 19-32, https://doi.org/ 10.1002/2013EF000165.

Wang, B., J. Liu, H.-J. Kim, P. J. Webster, and S.-Y. Yim, 2012: Recent change of the global monsoon precipitation (1979-2008). Climate Dyn., 39, 1123-1135, https://doi.org/10.1007/s00382-011-1266-z.

Xue, Y., T. M. Smith, and R. W. Reynolds, 2003: Interdecadal changes of 30-yr SST normals during 1871-2000. J. Climate, 16, 1601-1612, https://doi.org/10.1175/1520-0442-16.10.1601.

Zhang, Y., J. M. Wallace, and D. S. Battisti, 1997: ENSO-like interdecadal variability: 1900-93.J. Climate, 10,1004-1020, https:// doi.org/10.1175/1520-0442(1997)010<1004:ELIV>2.0.CO;2.

Zhang, X., F. W. Zwiers, G. C. Hegerl, F. H. Lambert, N. P. Gillett, S. Solomon, P. A. Stott, and T. Nozawa, 2007: Detection of human influence on twentieth-century precipitation trends. Nature, 448, 461-466, https://doi.org/10.1038/nature06025. 